\title{
Understanding how and why people participate in crowd events
}

Social Science Information $1-18$

(C) The Author(s) 2018

Reprints and permissions: sagepub.co.uk/journalsPermissions.nav DOI: $10.1177 / 05390184187577 \mid 4$ journals.sagepub.com/home/ssi

(\$SAGE

\section{Eduardo Cintra Torres}

Faculdade de Ciências Humanas, Universidade Católica Portuguesa, Portugal

\section{Sérgio Moreira}

Faculdade de Psicologia da Universidade de Lisboa, Portugal

\section{Rui Costa Lopes}

Instituto de Ciências Sociais da Universidade de Lisboa, Portugal

\begin{abstract}
The participation and collective effervescence in crowd events is a perennial issue in social sciences, however it has scarcely been researched from the point of view of the attendees. This article helps to fill the gap with an exploratory descriptive study based on a sample of I,553 respondents from 40 countries. The authors analyse seven different types of events and also describe the various participation levels, whether people go there alone or in company, and their reasons for attending. Globally, the results show several specific patterns: (a) the majority of the participants often go to collective events, but different events have different levels of participation; (b) people rarely go alone to collective events, but the company depends on the type of event; (c) although the results show it is not necessary to like the event to trigger participation, people have different reasons for going to different events. The article concludes with a cluster analysis that details the links between attendance, company, and reasons to attend, according to the socio-demographic factors.
\end{abstract}

\section{Keywords}

cluster analysis, collective effervescence, crowds, events, participation, survey

\footnotetext{
Corresponding author:

Eduardo Cintra Torres, Faculdade de Ciências Humanas, Universidade Católica Portuguesa, Palma de Cima, Lisboa, 1649-023, Portugal.

Emails: 139903037@fch.lisboa.ucp.pt; eduardocintratorres@gmail.com
} 


\section{Résumé}

La participation et l'effervescence collective dans les rassemblements publics sont des enjeux récurrents en sciences sociales; toutefois, cette question n'a guère été étudié du point de vue des participants. Cet article tente de combler cette lacune grâce à une étude descriptive exploratoire basée sur un échantillon de I 553 sondés de 40 pays.

Les auteurs dressent ici une typologie basée sur sept évènements distincts et décrivent les divers niveaux de participation qui expliquent les motivations des participants et si les gens se rendent à ces manifestations seul ou en groupe. Les résultats présentent globalement plusieurs schémas spécifiques: (a) la majorité des participants se rendent à des rassemblements publics; (b) les gens vont rarement seul à ces évènements et le choix de l'accompagnant ou des accompagnants dépend du type d'événement; (c) les résultats de l'enquête montrent que les motivations des participants sont variées et qu'il n'y a pas de nécessaire corrélation entre apprécier un événement et y participer.

Enfin, l'article conclut par une analyse typologique décrivant les liens entre fréquentation, présence et motivations à partir de variables socio-démographiques.

\section{Mots-clés}

analyse par grappes, effervescence collective, foules, évènements, participation, enquête

\section{Introduction}

Though crowd events have been an important topic in sociology since the last quarter of the 19th century, empirical studies about participation in this kind of event have been surprisingly scarce. While Durkheim (2001[1912]) was able to study collective effervescence through other scholars' anthropological enquires into 'primitive' societies, attempting to apply his conclusions to modern society, most studies of multitudinary events have been highly subjective or viewed from the 'outside'. People participating in the events have not been heard as often as the theorists themselves.

Collective effervescent events are one of the most perennial social activities. Today they pervade all spheres of life, from religion to politics, from all kind of leisure areas to entrepreneurially driven events. The 'conspicuous consumption' of the 'leisure class' (Veblen, 2009[1899]) has reached all levels of a 'society of spectacle' (Debord, 2013[1967]) marked by the 'eventification' of the public space in a media soaked life (Smith, 2016; Torres, 2013). Festivals and other crowd events have replaced religious rituals in 'a secular age' (Taylor, 2007). These ephemeral 'liminal' moments (Turner, 1995 [1969]) provide sociability, effervescence and feeling in crowd gatherings, wrenching people 'out of the everyday' and putting them in touch 'with something exceptional', beyond themselves (Taylor, 2007: 482). Participating in collective events is thus a vivid realization of the 'body being a medium for the constitution of social life' in the homo duplex condition (Shilling 2005; Durkheim 1973[1914]). They may work for individuals as an antidote to the 'culture of narcissism' and its focus on competitive self-interest (Lasch, 1979), based on 'superficial human relations' (Sennett, 2006: 181) and the 'rejection' of social groups and institutions (Silva, 2013: 125) by providing ephemeral but 
effervescent liminal occasions to interact and get away from daily life and its serious realm. These sort of theoretical speculations have been passed on largely untested.

Crowds are defined here as gatherings with a purpose (Pickering, 1984). This technical conception excludes any sombre views on people assembled, normally in public, open places, and prone to violence and disorder, as described in 19th- and early 20thcentury essays. Gabriel Tarde, one of the first scholars writing on crowds, dismissed his own view on the criminal crowd - and Gustave Le Bon's (1998[1895]) view for that matter - writing in 1898 that crowds were far from deserving the evil character that he himself, among others, attributed to them (Tarde, 1901). More than a century later, crowds 'are still a poorly studied and little understood social phenomena' (Drury \& Stott, 2013: 1) and remain a research area in need of structuring and hermeneutics. Still, social psychologists and sociologists have made sound advances in 'crowdology' (Drury \& Stott, 2013: 1), both in theory and theory history (Barrows, 1981; van Ginneken, 1992; Olaveson, 2001; Mariot, 2001; Schnapp \& Tiews, 2006; Borch, 2013, Torres, 2013) or in empirical studies of gatherings (Drury \& Stott, 2013). Some areas of crowd study have been particularly prolific: the history of the crowd itself (e.g. Rudé, 1967[1959]; Thompson, 1971; Harrison, 1988; Millar, 2002[1998]; Cross \& Walton, 2005; Mariot, 2006) and its representations in literature and the media (Schor, 1978; Carey, 1992; Plotz, 2000; Esteve, 2003; Jonsson, 2013; Torres, 2013). A series of monographs on sociology, psychology and other social science fields, including human geography, have studied specific areas of collective effervescence, such as religion, concerts and festivals, sports and demonstrations (Draper, 2014; Cariton-Ford, 1992; Weinberg \& Dwan, 2016; May, 2010; Novelli et al., 2013; Ryan \& Wollan, 2013; Smith, 2016; Giorgi et al., 2011; Horne \& Manzenreiter, 2006; Falassi, 1987). The development of social movement studies has in particular reintroduced the role of emotions in collective events, a research area with important developments in social psychology (Goodwin et al., 2001; von Scheve, 2011; Hopkins et al., 2016). In this study, we propose a step forward in the inquiry into participants in events by adding the comparative perspective between different kinds of events. If the crowd is construed as a social structure, albeit ephemeral, with specific functions, it is possible to explore how, among individuals in gatherings, there are 'structural relationships' (Collins, 1994[1985]: 187) that involve, not least, the actual physical pattern of who is in the presence of whom, how often and for what reasons.

To achieve a broad comparison with generalizable results, we decided to include types of crowd events that nowadays are not normally considered together, although all of them are similar by bringing people together for the same reason, but that were considered types of crowded situations in the early typologies of crowds, as in Le Bon (1998[1895]) and Tarde (1901). Our own choice of crowd events, including sports, religion, arts, music, pop/folk festivals and street demonstrations, was developed to cover the broadest spectrum possible and to allow for different individual and collective perspectives on participation in different types of events to spring from the empirical study. We considered the types chosen to cover the main situations when individuals in presentday society participate in crowd events.

The evolution of the capitalist society brought more leisure and an increased role for companies in all spheres of life, including the organization and management of crowd events of all kinds, originating an academic field - Event Studies - devoted to creating 
knowledge and theory about planned events and including crowd security and management techniques (Getz, 2007). Thus, the concept of events refers to gatherings with a purpose, but also with a new attention to the management of the collectives attending them. In this sense, there are no large, public events without a crowd, or at least without the intention of gathering a crowd. For that matter, we included in our study different types of gatherings with a purpose, regardless of their categorization as events in an entrepreneurially soaked conception.

In this article, we try to fill a gap in empirical crowd studies by providing statistical data stemming from the participation of individuals in crowd events, namely the participants' perceptions. The main objectives of this research were to quantify the participation of individuals in crowd events, the types of events they attend, if they participate alone or in the company of others, the relation between participation and age, gender, formal education, religion and economic income and, finally, the reasons for participating. This last issue was one of the study's most important objectives. A preliminary qualitative questionnaire helped to stabilize the options presented to the respondents. Being allowed to choose a first, a second and a third reason from a total of six, we believe we have covered the most meaningful motives for people to gather in crowd events and, simultaneously, have allowed for a straightforward comparison of responses across different events.

\section{Methodology}

\section{Questionnaire}

The questionnaire used in the present study was developed in English with students from 10 countries studying a contemporary themes bachelor course at the Faculty of Human Sciences of the Catholic University of Portugal (Lisbon). The questionnaire was translated under the professor's supervision into Bulgarian, English, Flemish, French, German, Greek, Italian, Polish, Portuguese and Spanish. It was composed of 37 questions about participating in events and socio-demographic data. Respondents were informed - through the questionnaire's instructions - about the goals of the study: 'to learn about people's participation in different kinds of events. This topic has not been studied thoroughly, so your answers will help us get a broad international and comparative view.' Instead of subjecting them to a definition of events, the respondents were presented with seven specific types of recognisable crowd events: 'football games' (hereafter FOOT), considering the sports events with the highest participation in the 10 countries of the students (football/soccer and American football); 'concerts, dance shows or musicals' (hereafter CONC); 'festivals (music, art, etc.)' (hereafter FEST); 'public religious events' (meaning regular religious services, except baptism, marriage and funereal services, hereafter RELG); 'local popular/folk events', a broad definition to allow for different realities in different countries (hereafter FOLK); 'big religious ceremonies, such as Fátima, Lourdes, Czestochowa, Mecca, and so on' (hereafter BIG RELG); and 'street demonstrations' (hereafter STREET). The seven types of events include a large array of situations involving different kinds of individual and collective engagement, at the spiritual, emotional and physical levels. We also tried to cover types of events that 
would potentially interest people from different socio-demographic groups (sex, age, income, country).

This diversity of events mirrors the three stages of ritual rites (van Gennep, 1977[1909]; Turner, 1995[1969]): separation from daily life, usual environmental and social conditions; liminality, or a transitory, collective situation when people are removed from both normal notions of time and space, in an atmosphere of communitas, sharing a common motive and an identity in a total or partial sense of egalitarianism; and reincorporation in the previous condition with reinforced optimism to face in daily life. Thus, this diversity of types enhances the possibility of a comparative perspective. ${ }^{1}$

\section{Sample and procedure}

Participants were invited through email and digital social networks, such as Facebook, to complete the questionnaire, using the software SURVS (https://survs.com). The survey was in the field from 19 November 2013 to 31 January 2014. We validated 1,553 complete replies, out of a total of 2,205 answers; 653 answers were excluded, corresponding to incomplete replies. Participants from 47 countries replied, with a majority being from the 10 countries represented on the course (Belgium, Bulgaria, France, Germany, Greece, Italy, Poland, Portugal, Spain, and United States). Nine countries, where respondents currently reside (Belgium, Bulgaria, France, Germany, Greece, Italy, Poland, Portugal, United States), obtained more than 40 replies each. More women (935, i.e. 61.1\%) than men (595, i.e. $38.9 \%$ ) participated. As expected, a significant number of respondents belong to the students' age group, but the respondents from other age groups were sufficient to use age as a variable. We divided the age groups in quartiles (up to 21, 22-25, 26-42, 43 years of age and over). We also collected data concerning years of education completed and family monthly income. Years of completed education were divided according to significant categories reflecting school cycles (up to 4 years, 5-9 years, 10-12 years, 13-17 years, 18 years and over). Family monthly income was divided into categories reflecting various socio-economic status.

\section{Data analysis approach}

Since the questions in our survey have rarely been included in other enquiries, a significant part of the data analysis is essentially descriptive. More specifically, we describe the response frequency of participation levels (never, once a year, 2-5 times a year, 6-12 times a year, more than once a month), going in the company of others or not (alone, with relatives, with friends, and acquaintances), and the reasons for participating (because I like the event, to share the moment with others, for the happiness of being there, to take a break from daily life, because I like being among the crowd, to have a better life) for each of the seven events included in the survey.

We also conducted a cluster analysis in order to explore the existence of specific event configurations on the attendance, going with others, reasons and socio-demographic dimensions. More specifically, a cluster analysis was set up for each event concerning the frequency of attendance, companionship and reasons to participate along with the following variables: sex, age, income and years of education completed. For the analysis, 
we used a hierarchical cluster procedure based on the Ward Method (Mooi \& Sarstedt, 2011; Tan, Steinbach \& Kumar, 2006). To select the number of clusters, we used a scree plot with the distance between the clusters and the number of clusters, and identified the point of inflection (i.e., the point where the distance between clusters stops varying with the increase in the number of clusters).

\section{Results}

\section{Participation levels}

First of all, we begin by presenting the frequencies and briefly analysing them (Table 1). The results reflect the different frequency of the events - for instance, some BIG RELG or FEST events take place only once a year - and people's relation with them. Of the seven types of multitudinary, crowd events mentioned in the survey, four (CONC, FEST, FOLK and RELG) had a yearly participation equal to or above 50\%; FOOT events attracted under half of the sample, contrasting with the big media coverage of this type of event. The two events with a stronger ideological profile, less connected with fun/ entertainment or implying a stronger will - BIG RELG and STREET - had the smallest adherence of the sample. Like FOOT, more than half of the respondents said they never go to BIG RELG and STREET events. Those participating in FOOT, BIG RELG and STREET events are more likely to go only once a year to each type. Attendance in CONC, FEST and FOLK is more frequent, from 2 to 5 times per year, while participation in RELG mainly occurs less than once a month.

In addition to the analysis of how often participants attend each of the seven types of events, we also analysed the absolute number of event types attended by each participant at least once a year (Table 2). The results show that only $2 \%$ of the sample never went to multitudinary events. The large majority $(87 \%)$ went to three or more types of events per year. The mode is four kinds of events. The frequencies show that the participation in multitudinary events is a normal activity for most individuals. Despite breaking their daily routine, mingling with the crowd can be said to be part of a life of normalcy.

To understand how the levels of participation vary according to socio-demographic variables, bivariate correlations were computed between age, sex, years of education completed, number of household members and family's monthly income, and the frequency of attending the different types of events. About FOOT attendance, there is a positive relationship $(r=.25, p<.01)$ with the sex of the respondents suggesting that

Table I. How often participants attend each of the seven events $(n=1553)$.

\begin{tabular}{lrrrrrrr}
\hline & FOOT & CONC & FEST & RELG & FOLK & BIG RELG & STREET \\
\hline Never & $57 \%$ & $8 \%$ & $19 \%$ & $41 \%$ & $27 \%$ & $76 \%$ & $69 \%$ \\
I/year & $18 \%$ & $20 \%$ & $32 \%$ & $16 \%$ & $32 \%$ & $16 \%$ & $15 \%$ \\
2-5/year & $15 \%$ & $46 \%$ & $40 \%$ & $17 \%$ & $33 \%$ & $7 \%$ & $12 \%$ \\
6- I 2/year & $4 \%$ & $19 \%$ & $7 \%$ & $7 \%$ & $6 \%$ & $1 \%$ & $3 \%$ \\
$>$ I/month & $6 \%$ & $7 \%$ & $2 \%$ & $19 \%$ & $2 \%$ & $0 \%$ & $1 \%$ \\
Total & $100 \%$ & $100 \%$ & $100 \%$ & $100 \%$ & $100 \%$ & $100 \%$ & $100 \%$ \\
\hline
\end{tabular}


Table 2. Total number of types of events participants attend per year $(n=1553)$.

\begin{tabular}{lc}
\hline Number of types of events & Percentage of participants \\
\hline $\mathbf{0}$ & $2 \%$ \\
$\mathbf{2}$ & $2 \%$ \\
$\mathbf{2}$ & $9 \%$ \\
$\mathbf{3}$ & $20 \%$ \\
$\mathbf{4}$ & $29 \%$ \\
$\mathbf{5}$ & $24 \%$ \\
$\mathbf{6}$ & $11 \%$ \\
$\mathbf{7}$ & $3 \%$ \\
Total & $100 \%$ \\
\hline
\end{tabular}

men are more likely to attend. Moreover, the results reveal that the older a person is, the less likely he/she is to attend FOOT events $(r=-.16, p<.01)$. Regarding RELG attendance, we also obtained correlations with $\operatorname{sex}(r=.11 ; p<.01)$, family income $(r=.15 ; p$ $<.01)$ and years of education completed $(r=.13 ; p<.01)$. In general, these results suggest that crowd events move away from traditional explanations regarding inescapable individual characteristics coercing people, and leave room for the autonomy that individuals can show as actors and conscious beings (Morin, 1998: 29). The interplay between participation levels varying according to socio-demographic variables will be further explored below.

\section{Going in the company of others}

The second question of the questionnaire for each type of event asked if people went alone, with relatives, friends or acquaintances, and how often (Table 3). The results show that most people never go alone to any type of event except for the RELG events. Those, who always go alone are residual in four types of events (FOOT, CONC, FEST and FOLK) and negligible in the other three (RELG, BIG RELG and STREET). In the case of FOOT events the participants are less likely to go unaccompanied (22\%). Once again, RELG is singled out with the highest level of participants claiming to go alone $(8 \%)$ and the majority of the respondents who go alone always, often or rarely (66\%). STREET events come close to having half the sample (49\%) participating alone always or on some occasions.

When going with company, there were different patterns for relatives, friends and acquaintances at each event. People are more likely to always participate in RELG (37\%) and BIG RELG (42\%) events with relatives than any of the other types of multitudinary events. STREET events show a striking difference from RELG: while $36 \%$ of respondents never participate in a STREET event with relatives, only $4 \%$ never attend RELG events with them. Family is nevertheless a part of the collective effervescence, since in all types of events, most of the respondents (from $73 \%$ to $97 \%$ ) go with relatives always or on some occasion.

Friends are an important social circle in the daily life of individuals that extends to liminal multitudinary situations. Only a residual part of the sample never goes with 
Table 3. Company that people go with for each of the seven events.

\begin{tabular}{lccccccc}
\hline & FOOT & CONC & FEST & RELG & FOLK & BIG RELG & STREET \\
& $n=658$ & $n=1430$ & $n=1262$ & $n=904$ & $n=1133$ & $n=370$ & $n=476$ \\
\hline Alone & & & & & & & \\
Always & $3 \%$ & $2 \%$ & $2 \%$ & $8 \%$ & $2 \%$ & $6 \%$ & $6 \%$ \\
Often & $5 \%$ & $8 \%$ & $10 \%$ & $25 \%$ & $6 \%$ & $8 \%$ & $13 \%$ \\
Rarely & $13 \%$ & $24 \%$ & $22 \%$ & $33 \%$ & $20 \%$ & $21 \%$ & $30 \%$ \\
Never & $78 \%$ & $66 \%$ & $66 \%$ & $34 \%$ & $72 \%$ & $65 \%$ & $51 \%$ \\
Relatives & & & & & & & \\
Always & $18 \%$ & $11 \%$ & $10 \%$ & $37 \%$ & $20 \%$ & $42 \%$ & $9 \%$ \\
Often & $26 \%$ & $37 \%$ & $31 \%$ & $40 \%$ & $44 \%$ & $36 \%$ & $25 \%$ \\
Rarely & $37 \%$ & $41 \%$ & $37 \%$ & $20 \%$ & $28 \%$ & $17 \%$ & $29 \%$ \\
Never & $19 \%$ & $12 \%$ & $22 \%$ & $4 \%$ & $8 \%$ & $5 \%$ & $36 \%$ \\
Friends & & & & & & & \\
Always & $30 \%$ & $33 \%$ & $40 \%$ & $9 \%$ & $33 \%$ & $18 \%$ & $39 \%$ \\
Often & $37 \%$ & $50 \%$ & $45 \%$ & $28 \%$ & $49 \%$ & $45 \%$ & $43 \%$ \\
Rarely & $28 \%$ & $14 \%$ & $13 \%$ & $39 \%$ & $16 \%$ & $23 \%$ & $14 \%$ \\
Never & $5 \%$ & $3 \%$ & $2 \%$ & $24 \%$ & $3 \%$ & $14 \%$ & $3 \%$ \\
Acquaintances & & & & & & & \\
Always & $6 \%$ & $4 \%$ & $6 \%$ & $6 \%$ & $7 \%$ & $9 \%$ & $13 \%$ \\
Often & $17 \%$ & $25 \%$ & $27 \%$ & $17 \%$ & $27 \%$ & $25 \%$ & $39 \%$ \\
Rarely & $33 \%$ & $40 \%$ & $39 \%$ & $34 \%$ & $37 \%$ & $30 \%$ & $32 \%$ \\
Never & $44 \%$ & $31 \%$ & $28 \%$ & $44 \%$ & $30 \%$ & $36 \%$ & $16 \%$ \\
\hline & & & & & & & \\
\hline
\end{tabular}

friends to events (from $2 \%$ to $5 \%$ ), except, again, for RELG (24\%) and BIG RELG $(14 \%)$ events. The importance of friendship emerges for one third of the respondents (from $30 \%$ to $40 \%$ ) in the other types of events, who claim to always participate in events with friends. Going with acquaintances is less common, although the majority of the sample claims to do it always, often or rarely. The respondents that never go with acquaintances show a smaller weight in STREET events (16\%), a feature that may indicate that individuality and ideological orientation are stronger than social circle affiliation in the case of this type of event.

In summary, for the individual go to a crowd event is a social event in two ways: the crowd and the company that they go with most of the time. Attending events with relatives and/or friends and/or acquaintances is a variable related to the kind of event.

\section{Reasons to participate}

The questionnaire allowed respondents to choose the three most important reasons to participate in events' (Table 4). These included a mainly rational reason ('I like the event'), social reasons ('To share the moment with others', 'I like being among the crowd', 'To take a break from daily life'), an emotional reason ('For the happiness of being there') and a spiritual reason ('To have a better life'). Only 'to take a break from daily life' and 'because I like being among the crowd' were not chosen as the first reason in any event. 
Table 4. Reasons why people go for each of the seven events.

\begin{tabular}{lcclcllr}
\hline & FOOT & CONC & FEST & RELG & FOLK & BIG RELG & STREET \\
& $n=658$ & $n=1430$ & $n=1262$ & $n=904$ & $n=1133$ & $n=370$ & $n=476$ \\
\hline First rank & & & & & & & \\
I like & $45 \%$ & $60 \%$ & $59 \%$ & $18 \%$ & $34 \%$ & $20 \%$ & $27 \%$ \\
To share & $19 \%$ & $11 \%$ & $10 \%$ & $33 \%$ & $24 \%$ & $20 \%$ & $15 \%$ \\
Happiness & $19 \%$ & $17 \%$ & $15 \%$ & $20 \%$ & $17 \%$ & $38 \%$ & $5 \%$ \\
Break & $7 \%$ & $6 \%$ & $7 \%$ & $6 \%$ & $14 \%$ & $4 \%$ & $3 \%$ \\
Crowd & $7 \%$ & $3 \%$ & $4 \%$ & $4 \%$ & $9 \%$ & $4 \%$ & $4 \%$ \\
Better life & $2 \%$ & $3 \%$ & $3 \%$ & $20 \%$ & $2 \%$ & $14 \%$ & $47 \%$ \\
Sum of three ranks & & & & & & & \\
I like & $84 \%$ & $85 \%$ & $87 \%$ & $52 \%$ & $72 \%$ & $64 \%$ & $70 \%$ \\
To share & $68 \%$ & $62 \%$ & $59 \%$ & $70 \%$ & $72 \%$ & $70 \%$ & $74 \%$ \\
Happiness & $66 \%$ & $70 \%$ & $70 \%$ & $73 \%$ & $64 \%$ & $85 \%$ & $42 \%$ \\
Break & $35 \%$ & $43 \%$ & $44 \%$ & $27 \%$ & $53 \%$ & $19 \%$ & $17 \%$ \\
Crowd & $31 \%$ & $19 \%$ & $21 \%$ & $19 \%$ & $27 \%$ & $13 \%$ & $26 \%$ \\
Better life & $11 \%$ & $21 \%$ & $20 \%$ & $60 \%$ & $12 \%$ & $49 \%$ & $71 \%$ \\
\hline
\end{tabular}

In the seven types of events, four different reasons were chosen by a majority of respondents as the first to justify attendance (Table 4). Liking an event for its content is not the first reason to go to most events for the majority of the respondents, except for CONC $(60 \%)$ and FEST (59\%) events; that is, those with the highest attendance, as we saw above. Liking the event is not the first reason to go for the large majority of those participating in RELG, BIG RELG and STREET events. Even for football-goers and folk eventgoers, despite being one of the main reasons, it is not mentioned as the first reason by the majority. The results show a common pattern in some of the types of events, such as FOOT, CONC, FEST and FOLK: 'to like', 'to share', and 'to live the moment with happiness' yield expressive replies. Again, RELG, BIG RELG and STREET events present a different pattern, showing that 'to have a better life' is more often invoked in these cases.

The total of the three ranks confirms that option: half or more of the sample chose 'having a better life' as one of the reasons to participate in BIG RELG (49\%), RELG $(60 \%)$ and STREET (71\%) events. In these last two types, 'having a better life' ranks as the second or third most cited reason to participate. BIG RELG and RELG stand out as the only types of event where the happiness to be there is the most mentioned reason $(85 \%$ and $73 \%)$. 'Sharing the moment with others' was most often mentioned regarding STREET (74\%), FOLK (72\%, the same as 'liking the event') and religious events. Although with lower results, the other reasons available in the questionnaire are nevertheless significant, including 'being among the crowd', which obtained above a fifth of the sample who participate in FEST (21\%), STREET (26\%), FOLK (27\%) and FOOT (31\%) events. We expected 'being among the crowd' to be an important reason to like participating in BIG RELG. But the result was totally the reverse, with the lowest level $(13 \%)$ in all types of events. The sum of the three ranks showed that no reason has been chosen by the totality of the sample in each event. 'Liking the event' gathers the most first, second and third choices in three types of events, while in the other three types, 
other reasons were preferred. At FOLK events, 'liking' and 'to share' tie as reasons to participate.

In sum, participating in different events is connected with a marked variety of reasons to go. More interestingly, we remark that it is not necessary to like an event to trigger participation in the event. As we see in Table 4, individuals might go to different events for different reasons.

\section{Event specific configurations}

In order to explore the existence of specific event configurations on the attendance, companionship, reasons and socio-demographic dimensions, a cluster analysis with these variables was performed (see online Appendix). The results revealed three clusters for FOOT, CONC, FEST, RELG, four clusters for FOLK and BIG RELG, and, finally, two clusters for STREET. We next detail and interpret the frequencies of the variables included in the cluster analyses for each of the clusters yielded by the analysis.

Football [FOOT] (see Table I in Appendix). Cluster 1 (C1) is the largest group (73\%) of the football-goers; it presents a fair distribution of age groups and a large number of people with high income and high schooling rates. $\mathrm{C} 1$ is not a frequent goer to the stadiums. This group does not attend football to get a better life $(0 \%)$, the reasons given being enjoyment of the game, sharing the moment or the simple happiness of being there; this last reason presents the highest value among clusters. $\mathrm{C} 1$ is an affluent group of moderate football-goers who enjoy the game with family and friends.

Cluster 2 (C2) is the smallest, 'oldest' and mostly feminine (53\%) cluster, with a mediumlow family income and fairly distributed schooling; it is the cluster of those who seldom go to the stadiums. They almost never go alone (5\%). They differ strongly from the other clusters concerning the first reason to go: they do not choose 'to like the event' as the first option $(0 \%)$; they choose 'because they like to be among the crowd', ' to break daily life', and 'to get a better life'. C2 is the group of people with an established life that does not particularly like football, but goes in company to benefit from the collective effervescence.

Cluster 3 (C3) is the youngest cluster (78\% under 26), with the lowest income and schooling rates; it is also the most masculine cluster $(64 \%)$ of the heavy goers $(40 \%$ attending the stadiums 6 or more times per year), going alone if necessary but especially with friends $(81 \%)$. This cluster yields a pattern of reasons to attend that is similar to $\mathrm{C} 1$. It is the group of young football lovers and heavy goers.

Summing up the results for the football clusters, groups with different socio-demographic characteristics show different patterns of frequency and company, but two of them, the youngest $(\mathrm{C} 3)$ and the most educated $(\mathrm{C} 1)$, representing $88 \%$ of the football-goers, choose the same three reasons as the first to attend games. Both show the same sociability, although one of them is a heavy-goers group, and the same psychological and social attitudes towards the event. Age seems to determine psycho-social attitudes, since the older group is very different in this respect. Income does not affect the frequency.

Concerts [CONC] (see Table 2 in Appendix). In C1, the largest group (50\%) is older, with a large income and the highest formal education. The group does not differ significantly 
in going alone or with company from the other clusters, but it is an almost unanimous cluster $(93 \%)$ in liking the concerts in the first place.

$\mathrm{C} 2$ is young-middle aged with the highest income of the three and a middle to high level of schooling. It differs a lot from the others in the reasons to attend: none of the 332 respondents in this cluster chose liking the concerts as the first reason to go. Almost half go for the happiness $(48 \%)$ and chose reasons that none of the other clusters chose as the first to go: 'to break daily life' (19\%), 'being among the crowd' (10\%) and 'to have a better life' $(10 \%)$.

$\mathrm{C} 3$ is the youngest cluster, with the lowest income and schooling, but attends concerts with a frequency similar to the others. While contrasting more with $\mathrm{C} 1, \mathrm{C} 3$ presents the same reasons to attend concerts.

Summing up concert clusters, the groups with important socio-demographic differences show the same three reasons to attend games. No socio-demographic variables explain differences in the reasons to attend.

Festivals [FEST] (see Table 3 in Appendix). C1 is the smallest group of the three and reunites people under $26(75 \%)$, with the lowest income and schooling rates. They go less to festivals than the others, go less alone, but more with friends. They go because they like the event and to share the moment.

$\mathrm{C} 2$ is the middle-aged group, and is the largest cluster (51\%), has the highest income, formal education and rate of frequency in attending festivals. It is the group that is almost unanimous in choosing 'liking festivals' as the first reason to go $(93 \%)$.

C3 has assorted socio-demographic characteristics, includes a third of the festivalgoers $(34 \%)$ and stands in the middle of the other clusters. It strongly differs from the others in the reasons to attend: nobody chose 'to like the festival' as the first reason to go, but mostly 'happiness' (45\%) and 'to break daily life' (20\%).

Summing up festival clusters, differences in socio-demographics may explain frequency, but not the reasons to attend: $\mathrm{C} 1$ and $\mathrm{C} 2$ are very different, but have the same reasons to go; $\mathrm{C} 3$, in the middle, presents radically different reasons to go.

Regular religious services [RELG] (see Table 4 in Appendix). C1 is the largest cluster $(40 \%)$, has higher average age, median income and the highest formal education among the clusters. It presents the second highest frequency. A third of the respondents goes alone and almost three out of four go with relatives. They like the event moderately, but more than the other clusters; they like to share the moment and are the cluster feeling happier in the event.

$\mathrm{C} 2$ is the youngest cluster, but nevertheless has a high income and a higher formal education. The cluster has a high participation in religious services $(37 \%$ go more than once a month). More than a third go alone (37\%), but they are also the group with the highest rates going in company with relatives (77\%) and acquaintances. We can say this is the cluster with the highest religious practice. Still, the members of this cluster neither consider 'liking the event' $(0 \%)$ or 'to share the moment' $(1 \%)$ as the first reason to attend. Two thirds of the cluster $(68 \%)$ go 'to have a better life' and next they mention 'being among the crowd' (13\%) and 'to break daily life' (10\%). 
C3 has an even age group distribution, but the lowest income and schooling. It is the cluster with the lowest participation in regular religious services (50\% go once a year), but when they go to a religious event, it is mainly (67\%) 'to share the moment'.

Summing up regular religious service clusters, two different clusters in socio-demographic variables and frequency, $\mathrm{C} 1$ and $\mathrm{C} 3$, have a similar pattern regarding the reasons to attend. The youngest cluster, $\mathrm{C} 3$, differs radically also from the other two in the first reason mentioned.

Popular/Folk events [FOLK] (see Table 5 in Appendix). Although the best solution for FOLK had four clusters, the smallest cluster had only nine respondents. For this reason, we limit our interpretation to the three remaining clusters.

$\mathrm{C} 1$, the largest cluster (54\%), is evenly distributed in age groups, has the highest income and schooling rates. The people in this group go in the first place because they like the event, to share the moment and for the happiness of being there.

$\mathrm{C} 2$, the cluster with fewer men, is also the youngest and with an average income. No participant mentions liking to attend or share the moment as a reason, mentioning 'breaking the daily life' (42\%) and 'being among the crowd' (40\%) as the main reasons to attend FOLK.

C3 is evenly distributed in age groups, has the lowest income and schooling rates and a slightly higher frequency than the other groups. The reasons to go are mainly 'to like', 'to share' and for the 'happiness' of being there.

Summing up FOLK, the three clusters present a similar attendance; two different clusters in socio-demographic variables $(\mathrm{C} 1$ and $\mathrm{C} 3)$ declared the same reasons as the first to go to the events. The younger cluster chose the opposite reasons.

Big religious ceremonies [BIG RELG] (see Table 6 in Appendix). C1 is the oldest cluster, and has an income above the average and the highest formal education among the clusters. Contrasting with the others, one in five respondents goes alone to the events. The reason most mentioned was happiness, but the cluster also presented the highest levels in the reasons 'to like the event' and 'to break daily life'.

$\mathrm{C} 2$ is the largest and youngest cluster, has an even distribution of income and a high level of schooling. Its choice of reasons is similar to $\mathrm{C} 1$.

C3 has the lowest income and schooling. It stands apart in strongly choosing 'happiness' as the first reason to participate (54\%). Like C1 and C2, it chose the first three reasons in the list.

$\mathrm{C} 4$ is a 'middle of the road' cluster in terms of socio-demographic variables, with a formal education higher than 9 years. Its choices to participate are radically different from the other clusters, totally concentrating on 'having a better life' (78\%) and 'being among the crowd' $(22 \%)$.

Summing up BIG RELG clusters, there are important differences in age distribution and schooling; going alone also contributed to cluster differentiation; frequency of attendance is rather similar among the clusters. Differences in socio-demographic variables and in attending the events alone do not explain the similarities of $\mathrm{C} 1$ and $\mathrm{C} 2$ in the choices of the first reason to attend. The same applies to C3. The last cluster is clearly separate in the reasons to go, which are totally opposed to those of the others. 
Street demonstrations [STREET] (see Table 7 in Appendix). Half of the $\mathrm{C} 1$ cluster is aged under $26(50 \%)$. It has a high income and the majority $(70 \%)$ has 13 years or more of formal education. Its members do not go frequently to street demonstrations, with $61 \%$ going once a year. 'To like' and 'to share' are the first reasons to go $(83 \%)$.

Half of the C2 cluster is aged under 26 (49\%). It declared a low income; the majority $(72 \%)$ has 13 years or more of formal education. More than half of the cluster participates between 2 and 12 times a year in street demonstrations (58\%). Almost all the members of the cluster $(92 \%)$ choose 'to have a better life' as the first reason to participate.

Summing up STREET clusters, the division is very clear. On the one hand, there are more affluent people participating less and enjoying and liking the events. On the other, there are less affluent people, participating more in the event and strongly giving a collective meaning to their participation.

\section{General discussion}

The aim of this article is to contribute to the understanding of participation and collective effervescence in crowd events, specifically, the levels of participation, going with others or alone and the reasons to attend in the context of seven different types of events.

First, our results show that participating in crowd events is a normal activity for almost all the individuals (98\%). Despite breaking their daily routine, mingling with the crowd can be said to be part of normal life.

Second, the results also show that going with company to crowd events is a normal activity for almost all individuals. Social company of relatives, friends or acquaintances varies according to the type of event. People may 'bowl alone' (Putnam, 2000), but not in the case of multitudinary, effervescent events. Family and friends are preexisting social circles, providing a buffer between individuals and crowds. The effervescent events may reinforce the social links between the individual and two social circles, the first circle uniting the person with family, friends and acquaintances, and the second circle (or the only one, if people go alone) with the ephemeral and anonymous crowd. Going to a crowd event is, for most individuals, a social event in two ways: the crowd and the people that they go with most of the time. Attending events with relatives and/or friends and/or acquaintances is a variable related to the kind of happening.

Third, the results show an expressive variety in the most important reason to participate in events. Four out of six different reasons were chosen as the first to justify participation in the seven types of events. We consider it particularly striking that to like the event is not the first reason mentioned by an expressive number of respondents, from $40 \%$ to $82 \%$, in each type of event. Other reasons, either individually driven or socially constraining, may take the lead. When the total of the three most important reasons for each type of event is considered, we find a homogeneity in the results of, on the one hand, the non-ideological types (FOOT, CONC, FEST, FOLK) and, on the other, the ideological events (RELG, BIG RELG and STREET). As different kinds of events trigger differences in the reasons to participate, we can assume that they feed different areas of individuality and the social life of individuals. 
Finally, organizing the seven sub-samples (one for each type of event) in the provided clusters led to verifying the relation between their socio-demographic characteristics, the frequency, company in participation and the first reason chosen to go to the events:

- $\quad$ Results show that age influences the frequency of attendance.

- Income may influence the attendance of some paid events, or free events that imply expenses, such as BIG RELG. However, comparing the cluster pattern of the seven kinds of event, different socio-demographics in clusters coexist with the same reasons to attend; and similar socio-demographics in clusters coexist with different reasons to attend. By simplifying, different people go for the same reasons and similar people go for different reasons.

- Going alone to the events shows a certain variety in three types of events and may explain differences between clusters in one of the types, but does not create a pattern in the three of them.

- Going with others never shows sharp differences, confirming that going with acquaintances, but especially relatives and friends, is a common feature of people going to crowd events.

- The sharpest differences in the first chosen reason to attend may be the main feature in the clusters. It shows that crowd events are occasions for people of different ages and backgrounds to gather in the same place with the same purpose. It also shows that crowd events provide a satisfaction, shown in the reasons to attend, that varies greatly and independently of people's background.

- In every type of event, there is at least one cluster with all its members not choosing liking the event and to have a better life as the first reason to attend.

Despite the importance of these results, we note that the fact that the present research was conducted through online surveying carries one specific concern considering the phenomenon under study. It might be the case that those who have internet access and social media profiles are more prone to socializing and thus attend more events. This may lead to an overestimation of the number of events that participants have reported attending. Nonetheless, the fact that the results yielded enough variance (including several participants with low levels of attendance) leads us to think that this may not have played a significant role (probably telling us more about the ubiquity of internet access and social media use). Furthermore, the inquirers were strongly invited to diversify the list of people they were to contact to reply to the survey. This resulted in a good representation in the sample of all groups of age, civil status, countries of current residence, years of completed education, income and also religiousness.

Another cautionary note regards the concern with the veracity of the answers. In fact, this is an issue common to all research conducted with explicit measures (Costa-Lopes \& Pereira, 2011). This particular context, however, carries two specificities that significantly minimize this concern. On the one hand, the fact that there is no researcher present may lead to a reduced concern with social desirability (thus, more honest responses). On the other hand, although the fact that we are dealing with online responses may make people more suspicious about whether or not their responses can be traced, the topic under study is not severely targeted with social norms and high concerns for self-image. 
Finally, online surveys do carry the extra concern that participants may be less involved with the research in general, as they may be carrying out other tasks (that the researcher is unaware of). Although aware of this risk, we consider it worth the risk if we take into account the contribution of such a method to attain large samples of respondents participating on a voluntary base (Kraut el al, 2004).

\section{Conclusion}

Crowd events are an occasion for different or similar people to deliberately gather at the same place with the same purpose and with the same or different reasons. It remains an essential condition of the fusion of individuals in a gathering that there is a pre-existing similarity of consciousness to build on (Durkheim, 2014[1893]). Nevertheless, in the events-soaked contemporary society, the similarity is provided or triggered by the content, be it a concert, a football game or a street demonstration, and the need to be in a crowd to break up daily life for different reasons and to strengthen the individual in that daily life.

In this sense, multitudinary occasions provide the reinforcement of social belonging in individuals. Mingling with the crowd is an antidote to daily isolation and works through living the events in the company of others, thus reinforcing a first circle of sociability. Crowds may not have the same cohesion today as when Durkheim and other crowd theorists wrote about them, due to the processes of individualization, multiplication and 'naturalization' of event situations, but individuals still need to mingle with the crowd and they probably do it more often than in the past. The resultant social renewal may not be univocal and felt as a consequence for collectives that are as ephemeral as the crowd event, but they nonetheless strengthen the social belonging of each individual and compensate for traits of contemporary society, such as loneliness and competition. Sharp differences in the reasons to attend events are a more important 'divider' of people in clusters than socio-demographics, and, at the same time, they 'unify' people of a different age, sex, income and formal education. Thus, collective effervescence functions as a social cement unknown or uncommon in other areas of social life.

\section{Acknowledgements}

The authors wish to thank Alice Ramos (ICS-UL) for her collaboration in the preparation of the questionnaire and UCP for allowing the institution's name and logo in the survey.

\section{Funding}

This work was partially supported by an FCT Grant - IF/00285/2014/CP1239/CT0002 - allocated to Rui Costa Lopes.

\section{Note}

1. The time allotted to discuss and translate the questionnaire with the students provided an opportunity for a valuable discussion concerning events, crowds and the specific questions involved in the questionnaire, which was adapted as a result of the discussion. Furthermore, a smaller, qualitative study with open questions was conducted by students using a small convenience sample (by email or social digital network) in another seminar at the same university 
to check the validity of the questions involved in the quantitative survey, providing satisfactory support for the validity and correctness of the questions.

\section{Supplemental material}

Online supplementary data is available at http://ssi.sagepub.com/supplemental.

\section{ORCID iD}

Eduardo Cintra Torres (iD) https://orcid.org/0000-0002-5736-8936

\section{References}

Barrows S (1981) Distorting Mirrors: Visions of the Crowd in Late Nineteenth-Century France. New Haven, CT: Yale University Press.

Borch C (2013) The Politics of Crowds: An Alternative History of Sociology. Cambridge: Cambridge University Press.

Carey J (1992) The Intellectuals and the Masses: Pride and Prejudice among the Literary Intelligentsia, 1880-1939. London: Faber and Faber.

Cariton-Ford SL (1992) Charisma, ritual, collective effervescence, and self-esteem. The Sociological Quarterly 33(3): 365-387.

Collins R (1994[1985]) Four Sociological Traditions. New York: Oxford University Press.

Costa-Lopes R, Pereira CR (2011) O Impacto da Norma Anti-Racista nas Respostas a Inquéritos sobre Preconceito. In António JHC, Policarpo V (eds) Os Imigrantes e a Imigração aos Olhos dos Portugueses: Manifestações de preconceito e perspectivas sobre a inserção de imigrantes. Lisbon: Universidade Católica Portuguesa/Fundação Calouste Gulbenkian, $169-187$.

Cross G, Walton JK (2005) The Playful Crowd: Pleasure Places in the Twentieth Century. New York: Columbia University Press.

Debord G (2013[1967]) Society of the Spectacle. London: Notting Hill Editions.

Draper S (2014) Effervescence and solidarity in religious organizations. Journal for the Scientific Study of Religion 53(2): 229-248.

Drury J, Stott C (2013) Crowds in the 21st Century. Perspectives from contemporary social science. London: Routledge.

Durkheim E (1973[1914]) The dualism of human nature and its social conditions. In: Durkheim E (ed.) On Morality and Society. Chicago: The University of Chicago Press, 149-163.

Durkheim E (2001[1912]) The Elementary Forms of Religious Life. Oxford: Oxford University Press.

Durkheim E (2014[1893]) The Division of Labour in Society. New York: Free Press.

Esteve M (2003) The Aesthetics and Politics of the Crowd in American Literature. Cambridge: Cambridge University Press.

Falassi A (1987) Festival: Definition and morphology. In Falassi A (ed.) Time out of Time: Essays on the Festival. Albuquerque: University of New Mexico Press, 1-10.

Getz D (2007) Event Studies. Theory, Research and Policy for Planned Events. Amsterdam \& London: Elsevier.

Giorgi L, Sassatelli M, Delanty G (2011) Festivals and the Cultural Public Sphere. London: Routledge.

Goodwin J, Jasper JM, Polletta F (2001) Passionate Politics. Emotions and Social Movements. Chicago/London: The University of Chicago Press.

Harrison M (1988) Crowds and History. Mass Phenomena in English Towns, 1790-1835. Cambridge: Cambridge University Press. 
Hopkins N, Stephen D, Reicher SD, et al. (2016) Explaining effervescence: Investigating the relationship between shared social identity and positive experience in crowds. Cognition and Emotion 30(1): 20-32.

Horne J, Manzenreiter W (2006). An Introduction to the sociology of sports mega-events. The Sociological Review 54(s2): 1-24.

Jonsson S (2013) Crowds and Democracy: The Idea and Image of the Masses from Revolution to Fascism. New York: Columbia University Press.

Kraut R, Olson J, Banaji M, et al. (2004). Psychological research online: Report of Board of Scientific Affairs' Advisory Group on the Conduct of Research on the Internet. American Psychologist 59(2): 105-117.

Lasch C (1979) The Culture of Narcissism: American Life in an Age of Diminishing Expectations. New York: Norton.

Le Bon G (1998[1895]) Psychologie des foules. Paris: Presses Universitaires de France.

Mariot N (2001) Les formes élémentaires de l'effervescence collective, ou l'état d'esprit prêté aux foules. Revue française de science politique 51(5): 707-738.

Mariot N (2006) Bains de foule. Les voyages présidentiels en province, 1888-2002. Paris: Belin.

May J (2010) Pilgrims on Tour: Collective Effervescence in Concerts (doctoral thesis). Michigan, MI: University of Michigan.

Millar F (2002[1998]) The Crowd in Rome in the Late Republic. (Jerome Lectures, 22). Ann Arbor, MI: University of Michigan Press.

Mooi E, Sarstedt M (2011) A Concise Guide to Market Research: The Process, Data, and Methods Using IBM SPPS Statistics. Berlin: Springer.

Morin E (1998) Sociologia. A Sociologia do microssocial ao macroplanetário. Portugal: Publicações Europa-América.

Novelli D, Drury J, Reicher S, Stott C (2013) Crowdedness mediates the effect of social identification on positive emotion in a crowd: A survey of two crowd events. PLoS ONE 8(11). Available at: e78983. doi:10.1371/journal.pone.0078983 (accessed 28 March 2017).

Olaveson T (2001) Collective effervescence and communitas: Processual models of ritual and society in Emile Durkheim and Victor Turner. Dialectical Anthropology 26(2): 89-124.

Pickering WSF (1984) Durkheim's Sociology of Religion: Themes and Theories. London: Routledge \& Kegan Paul.

Plotz J (2000) The Crowd: British Literature and Public Politics. Berkeley, LA: University of California Press.

Putnam R D (2000) Bowling Alone: The Collapse and Revival of American Community. New York: Simon \& Schuster.

Rudé G (1967[1959]) The Crowd in the French Revolution. Oxford: Oxford University Press.

Ryan W, Wollan G (2013) Festivals, landscapes, and aesthetic engagement: A phenomenological approach to four Norwegian festivals. Norwegian Journal of Geography 67(2). Available at: http://dx.doi.org/10.1080/00291951.2013.784352 (accessed 26 March 2017).

Schnapp JT, Tiews M (eds) (2006) Crowds. Stanford, CA: Stanford University Press.

Schor N (1978) Zola's Crowds. Baltimore, MD: Johns Hopkins University Press.

Sennett R (2006) The Culture of the New Capitalism. New Haven, CT: Yale University Press.

Shilling C (2005) Embodiment, emotions, and the foundations of social order: Durkheim enduring contribution. In: Alexander J, Smith P (eds) The Cambridge Companion to Durkheim. Cambridge: Cambridge University Press, 211-238.

Silva J (2013) Coming Up Short: Working-Class Adulthood in an Age of Uncertainty. Oxford: Oxford University Press.

Smith A (2016) Events in the City: Using Public Spaces as Event Venues. London: Routledge.

Tan PN, Steinbach M, Kumar V (2006). Introduction To Data Mining. London: Pearson Education. 
Tarde G (1901) L'opinion et la foule. Paris: Félix Alcan.

Taylor C (2007) A Secular Age. Cambridge, MA: Harvard University Press.

Thompson EP (1971) The Moral Economy of the English Crowd in the Eighteenth Century. Past and Present 50(1): 76-136.

Torres EC (2013) A Multidão e a Televisão. Representações Contemporâneas da Efervescência Colectiva. Lisbon: UCE.

Turner V (1995[1969]) The Ritual Process: Structure and Anti-structure. New York: AldineTransaction.

van Gennep A (1977[1909]) The Rites of Passage. London: Routledge.

van Ginneken J (1992) Crowds, Psychology, \& Politics, 1871-1899. Cambridge: Cambridge University Press.

von Scheve C (2011) Collective emotions in rituals: Elicitation, transmission, and a 'Matthew Effect'. In: Michaels A, Wulf C (eds) Emotions in Rituals. London: Routledge. Available at: http://www.polsoz.fu-berlin.de/soziologie/arbeitsbereiche/emotionen/team/pics_and_files/ Scheve_EmotionsRituals_PREPRINT.pdf (accessed 30 March 2017).

Veblen T (2009[1899]) The Theory of the Leisure Class. Oxford: Oxford University Press.

Weinberg MK, Dawn J (2016) If you're happy and you know it: Music engagement and subjective wellbeing. Psychology of Music 1(11). Available at: https:/www.iq-mag.net/wp-content/ uploads/2016/08/Psychology-of-Music-2016-Weinberg-0305735616659552.pdf (accessed 24 March 2017).

\section{Author biographies}

Eduardo Cintra Torres (PhD in Sociology, ICS-UL, 2010), is Visiting Assistant Professor at the Catholic University of Portugal and ISCTE-IUL. He is the author of 18 books, including From Multitude to Crowds (co-editor) (Peter Lang, 2015) and the author of book chapters and scientific articles published in Portugal, France, Brazil, the UK and Canada, including 'Durkheim's Concealed Sociology of the Crowd', Durkheimian Studies 20(1) (2014).

Rui Costa Lopes (PhD in Social Psychology, ISCTE, 2009) is a Research Fellow at the Institute of Social Sciences - University of Lisbon and a Visiting Assistant Professor at the Catholic University of Portugal. His research interests focus on intergroup relations, migrations, prejudice and social norms. His work has been published in outlets such as the European Journal of Social Psychology, British Journal of Social Psychology, International Review of Social Psychology, International Journal of Psychology and Routledge-edited books.

Sérgio Moreira (PhD in Social Psychology, ISCTE, 2012) is a consultant in environmental, social and health fields and a Visiting Assistant Professor in the Faculty of Psychology at the University of Lisbon and at Católica Lisbon School of Business \& Economics. He is interested in statistics, research methods and applied psychology. He has worked as a consultant with several public and private institutions and has published in outlets such as Environmental Psychology, Environmental Impact Assessment Review, and the British Medical Journal. 